\title{
Hierarchical representation learning for big complex multimedia data
}

Published online: 3 September 2019

(C) Springer Science+Business Media, LLC, part of Springer Nature 2019

Multimedia Tools and Applications gratefully acknowledges the editorial work of the scholars listed below on the special issue entitled "Hierarchical Representation Learning for Big Complex Multimedia Data."

Of 66 papers submitted to this issue, 22 were eventually accepted after a stringent peerreview process.

\section{Corresponding Guest Editor}

\section{Dr. Lin Wu}

The University of Queensland, Australia

Email: lin.wu@uq.edu.au

\section{Guest Editors}

Dr. Yang Wang

The University of New South Wales, Australia

Email: wangy@cse.unsw.edu.au

Prof. Xue Li

The University of Queensland, Australia

Email: xueli@itee.uq.edu.au

Prof. Junbin Gao

The University of Sydney, Australia

Email: junbin.gao@sydney.edu.au

Pulisher's note Springer Nature remains neutral with regard to jurisdictional claims in published maps and institutional affiliations 